\title{
SELEÇÃO DE CLONES DE FIGUEIRA cv. ROXO DE VALINHOS FORMADOS POR GEMAS IRRADIADAS ${ }^{1}$
}

\author{
MARIA GABRIELA FONTANETTI RODRIGUES², LUIZ DE SOUZA CORREA ${ }^{3}$, \\ PEDRO CESAR DOS SANTOS 3 , AUGUSTO TULMANN NETO ${ }^{4}$
}

RESUMO - A figueira (Ficus carica L.), pertencente à família das Moráceas, constitui-se numa das mais importantes frutíferas cultivadas, elevando o Brasil à condição de décimo maior produtor e exportador de figos do mundo. Porém, a ficicultura apresenta alguns problemas fitossanitários, além de, no Brasil, estar toda implantada com uma única cultivar, a Roxo de Valinhos, que produz frutos sem sementes, inviabilizando o melhoramento convencional. Nesse sentido, o melhoramento genético, com o uso de mutagênicos, passa a ser uma linha de pesquisa altamente importante, podendo contribuir enormemente para o desenvolvimento da cultura. Diante disto, o objetivo do presente trabalho foi selecionar mutantes em plantas de figueira formadas por estacas irradiadas com raios gama, a fim de aumentar sua variabilidade genética com relação ao desenvolvimento vegetativo e reprodutivo. Utilizaram-se plantas formadas por estacas originadas de gemas da cultivar Roxo de Valinhos irradiadas com raios gama, no irradiador tipo Gamma a 0,10 $\mathrm{m}$ do ápice, na dose de Gy com taxa de dose de $238 \mathrm{~Gy} / \mathrm{h}$. O experimento constou de 450 tratamentos, sendo cada planta formada considerada um tratamento, numerando-as sequencialmente de 1 a 450 e cultivadas em espaçamento de 2,5 x 1,5 m.. As avaliações foram realizadas a partir das características tanto das folhas quanto dos frutos, bem como da incidência das principais pragas e doenças da cultura nestas plantas. Da análise dos dados, conclui-se que há variabilidade genética entre os tratamentos e que algumas plantas são prováveis mutantes, mostrando-se assim com potencial para posteriores estudos, devendo ser testadas em plantios comerciais.

Termos para indexação: Ficus carica, radiação gama, mutação.

\section{FIG CLONES SELECTION OF cv. ROXO DE VALINHOS OBTAINED BY IRRADIATED BUDS}

\begin{abstract}
The fig tree (Ficus carica L.) is a fruit tree of great world importance and, therefore, the genetic improvement becomes an important field of research for the crop improvement, being necessary to gather information on this species, mainly regarding its genetic variability so that appropriate propagation projects and management are made. However, the fig, in Brazil, is all produced from only one cultivar, Roxo de Valinhos, which produces seedless fruit, making impossible the conventional breeding. So, the fig breeding through induced mutagenic becomes a very important research line, greatly contributing to the fig culture development. The objective of this study was to select fig plants formed by cuttings treated with gamma ray. The plants used were obtained from buds of the cv. Roxo de Valinhos. The cuttings were irradiated with gamma rays in an irradiator Gamma Cell at $10 \mathrm{~cm}$ from the tip of the cutting, at doses of 30 Gy with dose rate of $238 \mathrm{~Gy} / \mathrm{h}$. The experiment consisted of 450 treatments, where each formed plant was a treatment. The treatments were numbered sequentially from 1 to 450 and spaced $2.5 \times 1.5 \mathrm{~m}$. It was evaluated the vegetative and the fruits characteristics, and the incidence of major crop pests and diseases. The analysis data showed that there is genetic variability among treatments and that the plants under numbers 1 , $5,20,79,164,189,194,201,221,214,258,301,322,392,433$ and 440 are probably genetic mutants that should be tested as commercial orchards.
\end{abstract}

Index terms: Ficus carica, figs, gamm radiation, mutation.

\footnotetext{
1(Trabalho 120-11). Recebido em: 06-04-2012. Aceito para publicação em: 29-03-2012.

${ }^{2}$ Eng. Agrônoma. MSc. Universidade Estadual Paulista (UNESP), Ilha Solteira-SP. Bolsista FAPESP. E-mail: gabrielafontanetti@hotmail.com ${ }^{3}$ Docentes do Depto. Fitotecnia, Tecnologia de Alimentos e Socioeconomia da FEIS-UNESP. E-mails: lcorrea@agr.feis.unesp.br; santospc@agr.feis.unesp.br

${ }^{4}$ Docente do Centro de Energia Nuclear na Agricultura (CENA)/Universidade de São Paulo (USP), Piracicaba-SP, E-mail: tulmann@cena.usp.br
} 


\section{INTRODUÇÃO}

A figueira Ficus carica L constitui-se, atualmente,em uma das mais importantes frutíferas cultivadas, evoluindo rapidamente de pequenos pomares domésticos para produção em larga escala, fato que elevou o Brasil à condição de segundo maior produtor e exportador de figos do mundo, com cerca de 800 toneladas de frutos exportados para a Europa (NORBERTO et al., 2001).

Pertencente à família Moraceae, a figueira comum é uma frutífera e apresenta um número diploide (2n) de cromossomos iguais a 26. Incluem-se nesta família cerca de 60 gêneros e mais de 2.000 espécies entre árvores, arbustos, trepadeiras e pequenas ervas (PEREIRA; NACHTIGAL, 1999). No Estado de São Paulo, principal produtor brasileiro de figo, existem cerca de 25 cultivares de figueira, das quais a única cultivada comercialmente é a Roxo de Valinhos, de grande valor econômico, caracterizando-se pela sua rusticidade, vigor e produtividade (MAIORANO et al., 1997).

Os programas de melhoramento de figueira por métodos convencionais para a obtenção de novas cultivares são raros em muitos países, como no Brasil, por exemplo, pela pequena variabilidade genética encontrada e pela dificuldade de obtenção de plantas originadas pela fusão de gametas, uma vez que a vespa Blastophaga psenes, responsável pela polinização natural, devido às condições climáticas, não existe no País (FERREIRA et al., 2009). Com isso, a seleção e a recuperação de um genótipo que associe as características básicas da cultivar original e as que se pretendiam introduzir, torna-se muito difícil, podendo o uso de mutagênicos trazer bons resultados.

A utilização de agentes mutagênicos físicos e químicos pode ser de fundamental importância para criação e incorporação de novos genes de interesse agronômico, podendo resultar em genótipos mais estáveis e mais adaptados às condições edafoclimáticas do Sul do Brasil (COIMBRA et al., 2005). A frequência e a saturação de mutações podem ser reguladas através da variação da dose dos agentes mutagênicos (JANDER et al., 2003; MENDA et al., 2004). Agentes mutagênicos podem induzir a diferentes extensões de lesões genômicas, variando desde mutações de bases do DNA até inserções ou deleções de fragmentos inteiros (MACKENZIE et al., 2005; KIM et al., 2006).

De acordo com Coimbra et al. (2004), a técnica de indução de mutação por irradiação tem sido muito empregada em programas de melhoramento de plantas. A mutação por irradiação pode ser utilizada com o objetivo de modificar algumas características para que se tornem úteis ao homem através de alterações alélicas ao nível do DNA, com a obtenção de variações genéticas.

A mutação induzida tem sido utilizada para elevar as frequências de mutações e variações que podem ser induzidas tanto por tratamento com mutagênicos químicos como por substâncias alquilantes quanto físicos, como radiações ionizantes (PREDIERI, 2001). Porém, a radiação gama pode ser considerada como um dos principais indutores de mutação e de aberrações cromossômicas estruturais (PIMENTEL, 1990).

De acordo com Rocha et al. (2009), nas últimas quatro décadas, foram criadas aproximadamente 2.250 cultivares de diferentes espécies oriundas do uso de agentes mutagênicos, impactando significativamente tanto na área cultivada quanto na economia mundial. Kerkadze (1987) obteve um mutante de figueira (variedade Bolinzhir) através de irradiação gama, mostrando a viabilidade da técnica.

Diante do exposto, o objetivo do presente trabalho foi selecionar mutantes em plantas de figueira formadas por estacas irradiadas com raios gama, a fim de aumentar sua variabilidade genética com relação ao desenvolvimento vegetativo e reprodutivo.

\section{MATERIAL E MÉTODOS}

O experimento foi conduzido no município de Selvíria-MS, apresentando como coordenadas geográficas $20^{\circ} 22^{\prime}$ de Latitude Sul e $51^{\circ} 22^{\prime}$ de Longitude Oeste, com altitude ao redor de $335 \mathrm{~m}$. De acordo com Köeppen, o clima da região é Aw, apresentando temperatura média anual de $24,45^{\circ} \mathrm{C}$ (média das máximas de $27,5^{\circ} \mathrm{C}$ e das mínimas de $21,4^{\circ} \mathrm{C}$ ). A umidade relativa do ar está ao redor de $64,8 \%$ (média anual).

As adubações foram realizadas de acordo com análise de solo e recomendações de Raij et al. (1997), na projeção da copa das figueiras, com o terreno desprovido de cobertura morta. Após aplicação, colocou-se novamente a cobertura morta (acícula de Pinus), com o intuito de proteger o solo contra erosão, manter sua umidade e controlar plantas daninhas.

O tratamento fitossanitário constou de aplicações quinzenais de Calda Bordalesa (1\%), bem como $0,052 \mathrm{~kg}$ de Mancozeb (i.a.), visando a controlar especialmente a ferrugem da figueira (Cerotelium fici Cast.) e 0,060 kg de Methyl Parathion (i.a), para o controle da broca-da-figueira (Azochis gripusalis Walk.), ambas as concentrações para cada 100 litros de água.

A irrigação foi feita com uso de uma fita go- 
tejadora, 3 vezes por semana, com uma precipitação média de $2,0 \mathrm{~mm} / \mathrm{h}$, atingindo uma faixa de $50 \mathrm{~cm}$ de largura na linha de plantio.

O experimento foi instalado utilizando-se de 450 estacas de figueira que, de acordo com a origem, cada planta formada por elas pode ser um mutante. Previamente, estacas de figueira da cultivar Roxo de Valinhos, com $40 \mathrm{~cm}$ de comprimento, foram irradiadas a $10 \mathrm{~cm}$ do ápice com raios gama na dose de 30 Gy, com taxa de dose de $238 \mathrm{~Gy} / \mathrm{h}$, no irradiador tipo Gamma Cell, como descrito por Santos et al. (1997).

As estacas irradiadas foram enraizadas, formando novas plantas, e as gemas irradiadas destas estacas deram origem a ramos que foram podados por 6 vezes consecutivas; e somente nesse momento é que foram retiradas as 450 estacas para a instalação do presente trabalho, portanto na geração M1V6.

$\mathrm{O}$ experimento foi realizado com 450 tratamentos, numerando as plantas formadas, sequencialmente, de 1 a 450, sendo, portanto, cada uma delas um tratamento, no espaçamento $2,5 \times 1,5 \mathrm{~m}$, onde as mesmas se desenvolveram em solo com histórico de nematoides, conduzidas com 6 ramos e avaliadas a partir do $3^{\circ}$ ano após plantio no campo.

Nas folhas, foram avaliados: número de lobos por folha; comprimento $(\mathrm{cm})$ e largura $(\mathrm{cm})$ do limbo foliar; e comprimento $(\mathrm{cm})$ do pecíolo das folhas, utilizando-se de régua métrica.

Nos frutos, foram avaliados: formato dos frutos (alongado, oblongo piriforme ou oval), bem como seu comprimento $(\mathrm{cm})$, utilizando-se de régua métrica; e diâmetro $(\mathrm{cm})$, utilizando-se de um paquímetro; comprimento $(\mathrm{cm})$ do pedúnculo, com o uso de uma régua métrica, considerando-os curto (até $1 \mathrm{~cm})$, médio (1 a $2 \mathrm{~cm})$, longo $(2 \mathrm{a} 4 \mathrm{~cm})$ e muito longo (maior que $4 \mathrm{~cm}$ de comprimento); tamanho do ostíolo (grande $>0,5 \mathrm{~cm}$; médio 0,25 a $0,5 \mathrm{~cm}$ e pequeno $<0,25 \mathrm{~cm}$ de diâmetro); ostíolo aberto (possível ver interior do fruto) ou fechado; e cor da polpa de cada fruto, identificando as cores: vermelha, rosa ou âmbar.

Com relação a pragas e doenças, avaliaram-se a incidência de ferrugem, por meio da área ocupada com pústulas no interior de um círculo $(2,5 \mathrm{~cm}$ de diâmetro), colocado à direita na página inferior das folhas; broca-da-figueira, sendo considerada a planta que apresentasse pelo menos um ramo ou fruto com dano causado por broca (ponteiro ou frutos jovens perfurados); e nematoide, considerando portadoras de nematoides as plantas que apresentavam galhas no sistema radicular.

\section{RESULTADOS E DISCUSSÃO}

As avaliações realizadas nas folhas das 450 plantas do experimento indicaram que todas apresentaram cinco lobos maiores e dois menores por folha, o que está de acordo com a descrição realizada por Medeiros (2002) para a cultivar Roxo de Valinhos, que se caracteriza também por apresentar cor verdeescura; textura compacta, um tanto rígida; margem crenada; sino peciolar em forma de lira e pecíolo longo. Desta forma, a partir dessa característica, não é possível visualizar qualquer possível mutação.

Com relação ao tamanho das folhas, constatou-se que houve variações entre os tratamentos. Assim, o comprimento das folhas variou entre $7 \mathrm{e}$ $24 \mathrm{~cm}$, tendo como média $11,49 \mathrm{~cm}$. A largura das folhas variou entre 6 e $12,5 \mathrm{~cm}$, tendo como média $12,35 \mathrm{~cm}$.

O tamanho das folhas e sua simetria, na figueira comum, variam entre plantas e dentro de uma mesma planta em função da altura (base, meio e ápice) e posição (interior e exterior). As folhas externas são maiores que as internas, e por estarem mais sujeitas às variações de temperatura, luz e transpiração, são mais assimétricas que folhas internas segundo COWART E GRAHAM (1999). Estes autores acrescentam que acharam diferenças significativas também em assimetria de folhas entre plantas.

Em que pese pelas constatações de Cowart e Graham (1999) não serem o comprimento e largura das folhas boas características para avaliar mutações, vale lembrar que os maiores valores podem auxiliar juntamente com outras características, na determinação de possíveis mutações. Com relação aos menores valores, é importante salientar que os mesmos podem ser devido à atuação dos nematóides, uma vez que todas as plantas apresentaram nematoides. Os maiores valores para o comprimento das folhas foram obtidos com as plantas $2 ; 287 ; 368 \mathrm{e}$ 448 (maiores que $21 \mathrm{~cm}$ ) e para a largura das folhas foram as plantas $95 ; 287 ; 368 ; 370$ e 448 (maiores que $23 \mathrm{~cm}$ ). Na avaliação do comprimento dos pecíolos, verifica-se que houve variações, sendo maiores nas plantas $250 ; 287 ; 368$ e 370, cujos valores são, respectivamente, 16,$5 ; 17 ; 18$ e $15 \mathrm{~cm}$. No entanto, essas variações acompanham proporcionalmente o tamanho das folhas, não evidenciando desta forma qualquer efeito de mutação.

Com relação aos frutos, verifica-se que houve variações no formato dos frutos produzidos nas diferentes plantas do experimento. Na cultivar Roxo de Valinhos predomina frutos com formato oblongo piriformes, de pescoço curto e grosso, praticamente 
sem limite de separação com o corpo do receptáculo (RIGITANO, 1955). No entanto, não se encontram outros formatos, especialmente o alongado, como os encontrados nas plantas de números 301 e 440 (Figura 1). Nessas plantas, o formato é tão proeminente que permite colocá-las como sendo provavelmente mutantes.

$\mathrm{Na}$ cultivar Roxo de Valinhos predomina frutos com pedúnculo pequeno e médio, segundo Rigitano (1955). Não se encontram outros tamanhos, especialmente pedúnculo grande (muito longo), como os encontrados na planta de número 433 (Figura 2), o que facilita a colheita manual e aumenta a vida de prateleira do fruto. Tal fato permite colocar essa planta como sendo provável mutante.

De acordo com os valores de comprimento dos frutos observados na Figura 3, verifica-se que houve variações entre os frutos produzidos nas diferentes plantas do experimento. Os valores variaram entre 2,5 e 7,0 cm, para uma média de $4,88 \pm 0,72$. Baseado na Figura 4, percebe-se que o mesmo ocorreu para o diâmetro dos frutos, sendo que neste a variação foi de 2,5 a $5,5 \mathrm{~cm}$, para uma média de 4,24+_0,48. Dentre as plantas estudadas, destacam-se pelo maior tamanho do fruto as seguintes plantas: $221 ; 214 ; 301 ; 322 ; 392 ; 433$ e 440. O tamanho desses frutos pode provavelmente ser devido à mutação.

Com relação ao ostíolo, várias plantas apresentaram-no pequeno ou fechado, porém as plantas cujos frutos se desenvolveram de forma normal e que apresentaram ostíolo além de pequeno, também fechado, foram as de números $1 ; 5 ; 20 ; 79 ; 164 ; 189$; 194; 201 e 258, como mostram as Figuras 5 e 6. De modo geral, a cultivar Roxo de Valinhos apresenta ostíolo grande e muito aberto, com tendência de rachaduras na casca dos figos quando totalmente maduros. Essa característica propicia fácil e direto acesso da mosca do figo ao conteúdo carnoso dos frutos para oviposição (RAGA et al., 2003). As características das plantas mencionadas permitem colocá-las como sendo prováveis mutantes.

Verificou-se ainda que as plantas $1 ; 5 ; 43$; $50 ; 56 ; 58 ; 103 ; 194$ e 220 apresentaram polpa cor âmbar. De acordo com Rigitano (1955), os frutos da cultivar Roxo de Valinhos apresentam a polpa de coloração róseo-avermelhada característica, com cavidade central, sucosa, macia e de sabor agridoce agradável. A coloração clara, ou mais precisamente âmbar, não é encontrada na cultivar. Por outro lado, essa característica altera-se no decorrer do período de maturação em função do clima, especialmente da temperatura. Desta forma, é necessário um número e período maior de avaliações para se ter um resultado mais seguro.

Quanto ao ataque de pragas e doenças, verificou-se uma grande quantidade de plantas não atacadas pela Broca-do-Ponteiro (Azochis gripusalis). A cultivar em estudo é atacada por esta praga que causa a morte dos ponteiros, bem como de frutos novos. Por outro lado, em ataques severos, encontram-se, em determinados momentos, plantas não atacadas na cultivar Roxo de Valinhos. Desta forma, é importante avaliar as plantas por vários anos, para que se possa ter um resultado mais seguro sobre resistência ou simples escape. Verificou-se ainda que todas as plantas do trabalho apresentaram ferrugem, sendo que a intensidade esteve em todas as plantas acima de $20 \%$ da área foliar, o que não difere do que ocorre com a cultivar Roxo de Valinhos, quando submetida aos controles mais comuns, como os realizados no presente trabalho.

Pelas avaliações realizadas, pode-se constatar que todas as plantas foram atacadas por nematoides formadores de galhas, evidenciando que são suscetíveis ao mesmo. A amostra de raízes e de solo da área experimental analisada mostrou a presença de Meloidogyne incognita e Rotylenchulus reniformes em ambas as amostras, não sendo possível a seleção de plantas resistentes a essa praga.

De acordo com Latado et al. (2001), em trabalhos de melhoramento de frutíferas usando indução de mutações, após a obtenção de mutantes, devem-se analisar a estabilidade genética para a característica mutada e também a ocorrência de alterações em outras características, antes da liberação como nova cultivar. Tal estabilidade pode ser detectada através de uma análise cuidadosa, por vários anos, de plantas obtidas a partir de ramos da planta mutante, propagados vegetativamente, em plantios comerciais. 

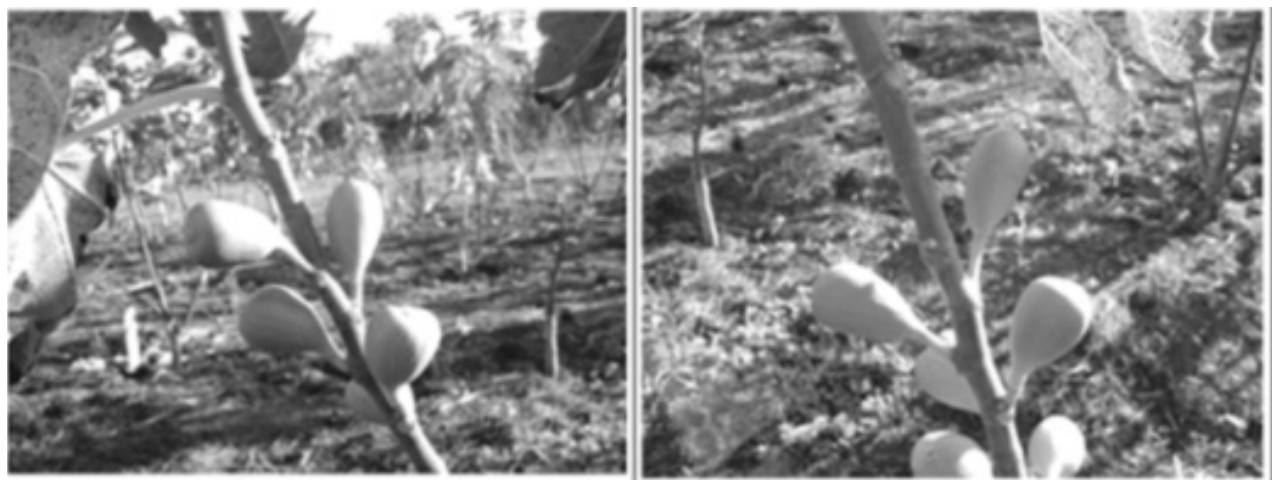

FIGURA 1 - Frutos de figueira com formato alongado encontrados nas plantas números 301 e 440 . Ilha Solteira.

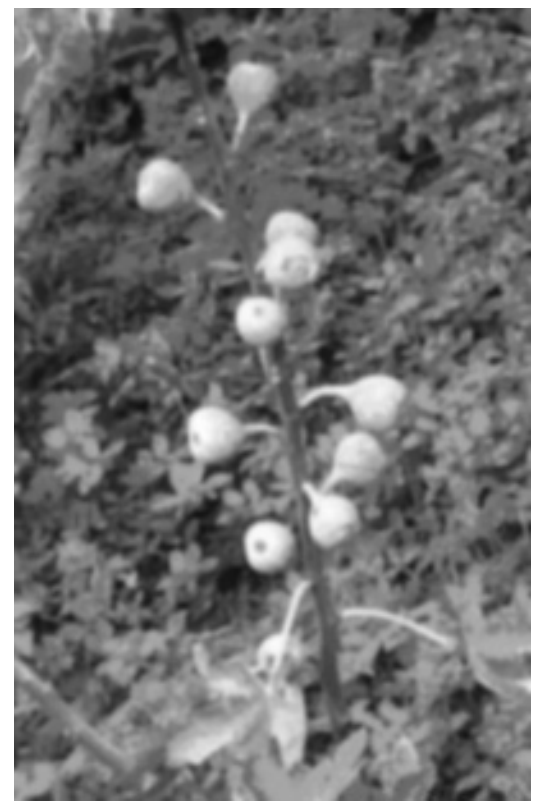

FIGURA 2 - Frutos de figueiras com pedúnculos muito longo encontrados na planta número 433. Ilha Solteira.

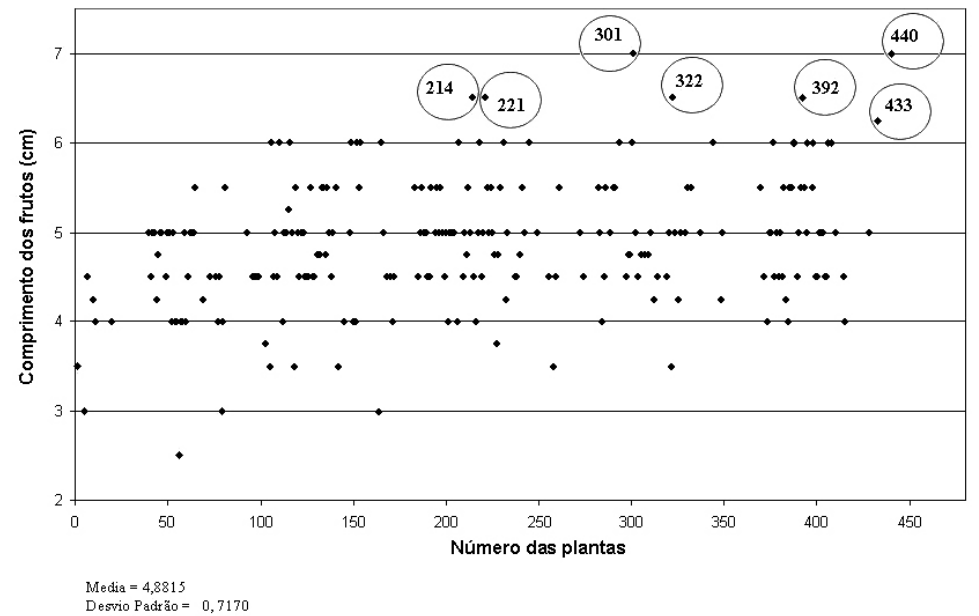

FIGURA 3 - Comprimento médio dos frutos produzidos, nas diferentes plantas de figueiras. 


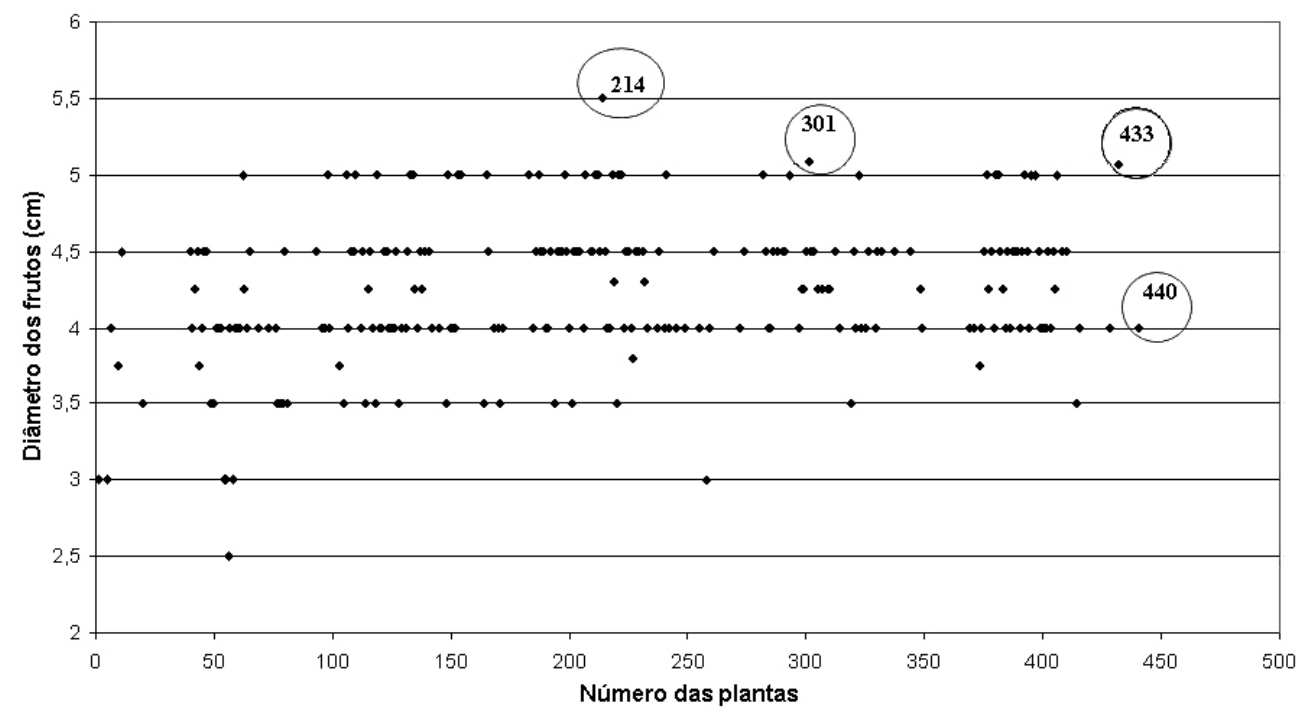

Media $=4,2442$

Desvio Padrão $=0,4827$

FIGURA 4 - Diâmetro médio dos frutos produzidos, nas diferentes plantas de figueiras.

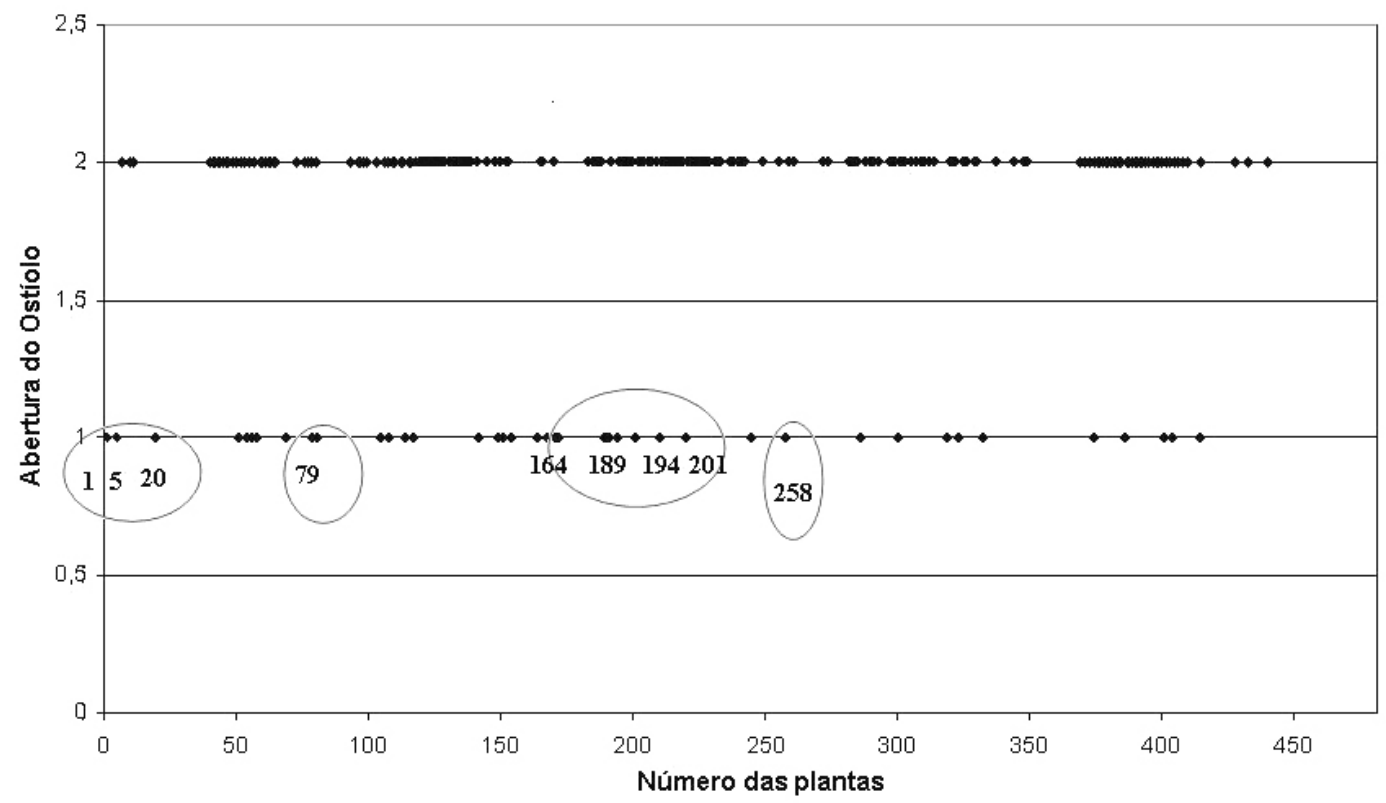

FIGURA 5 - Abertura do ostíolo do fruto ( 1 - fechado e 2 - aberto), nas diferentes plantas de figueiras. 


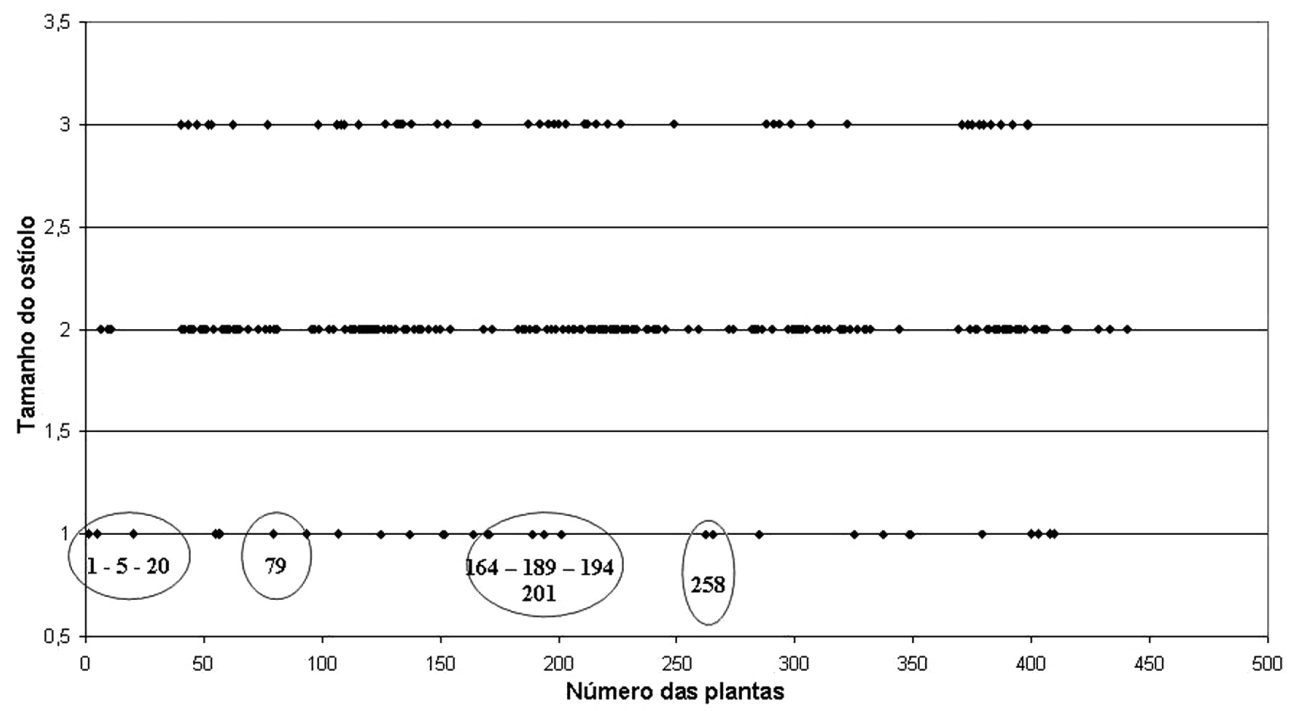

FIGURA 6 - Tamanho do ostíolo do fruto (1- pequeno, 2- médio e 3-grande), nas diferentes plantas de figueiras.

\section{CONCLUSÕES}

1-A indução de mutação com raios gama permite a seleção de plantas de figueira como sendo possíveis mutantes.

2-A radiação gama melhora parcialmente o porte, bem como a produtividade, qualidade dos frutos e potencial para diminuição de pragas e doenças em plantas de figueira.

3-As plantas de número $1 ; 5 ; 20 ; 79 ; 164$; $189 ; 194 ; 201 ; 214 ; 221 ; 258 ; 301 ; 322 ; 392 ; 433$ e 440 foram selecionadas como mutantes, devendo ser testadas em plantios comerciais, juntamente com a cv. Roxo de Valinhos, especialmente aquelas com formatos de frutos diferentes (301 e 440), pedúnculo longo (433), ostíolo pequeno e fechado (189) e frutos grandes (214).

\section{AGRADECIMENTOS}

À Fundação de Amparo à Pesquisa do Estado de São Paulo (FAPESP), pela concessão de bolsa de estudo para a realização do presente trabalho.

\section{REFERÊNCIAS}

COIMBRA, J.L.M.; CARVALHO, F.I.F.; OLIVEIRA, A.C. Genetic variability in populations of oat induced by chemical and physical mutagenic agents. Crop Breeding And Applied Biotechnology, Viçosa, MG, v.4, p.48-56, 2004.

COIMBRA, J.L.M.; CARVALHO, F.I.F.; OLIVEIRA, A.C; SILVA, J.A.G.; LORENCETT, C. Comparação entre mutagênicos químico e físico em populações de aveia.Ciência Rural, Santa Maria, v.35, n.1, p.46-55, 2005.

COWART, N. M.; GRAHAM, J.H. Within- and among-individual variation in fluctuating asymmetry of leaves in the fig (Ficus carica L.). International Journal of Plant Sciences, Chicago, v.160, n.1, p.116-121, 1999.

FERREIRA, E.A.; PASQUAL, M.; TULMANN NETO, A. In Vitro sensitivy of fig plantlets to gamma ray. Scientia Agricola, Piracicaba, v. 66, n.4, 2009.

KERKADZE, I.G. Radiation mutagenesis in subtropical crops. Radiatsionnyi Mitagenez-I-EgoRol-V-Evolutsii-I-Selektsii, p.231-254, 1987. 
JANDER, G.; BAERSON, S.R.; HUDAK, J.A.; GONZALEZ, K.A.; GRUYS, K.J.; LAST, R.L. Ethylmethanesulfonate saturation mutagenesis in Arabidopsis to determine frequency of herbicide resistance. Plant Physiology, Rockville, v.131, p.139-146, 2003.

KIM, Y.; SCHUMAKER, K.S.; ZHU, J.K. EMS mutagenesis of Arabidopsis. Methods in Molecular Biology, New York, v. 323, p. 101-103. 2006.

LATADO, R.R.; TULMANN NETO, A.; ANDO, A.; IEMMA, A.F.; POMPEU JUNIOR, J.; FIGUEIREDO, J.O.; PIO, R.M.; MACHADO, M.A.; NAMEKATA, T.; CERAVOLO, L.; ROSSI, A.C. Mutantes de laranja 'Pera' com número reduzido de sementes, obtidos através de mutações induzidas. Revista Brasileira de Fruticultura, Jaboticabal, v.23, p.339-344, 2001

MACKENZIE, J.L.; SAADÉ, F.E.; LE, Q.H.; BUREAU, T.E.; SCHOEN, D.J. Genomic mutation in lines of Arabidopsis thaliana exposed to ultraviolet-B radiation. Genetics, Austin, v. 171, p. 715-723, 2005.

MAIORANO, J. A.; ANTUNES, L. E. C.; REGINA. M. de A.; ABRAHÃO, E.; PEREIRA, A. F. Botânica e caracterização de cultivares de figueira. Informe Agropecuário, Belo Horizonte, v. 18, n. 188, p. 22-24, 1997.

MEDEIROS, A.R.M. Figueira (Ficus carica l.) do plantio ao processamento caseiro. Pelotas: Embrapa, 2002. 16p. (Circular Técnica, 35).

MENDA, N.; SEMEL, Y.; PELED, D.; ESHED, Y.; ZAMIR, D. In silico screening of a saturated mutation library of tomato. Plant Journal, Oxford, v.38, p.861-872, 2004.

NORBERTO, P. M.; CHALFUN, N. N. J.; PASQUAL, M.; VEIGA, R. D.; PEREIRA, G. E.; MOTA, J. H.. Efeito da época de estaquia e do aib no enraizamento de estacas de figueira (Ficus carica L.). Ciência Agrotecnia, Lavras, v.25, n.3, p.533541, 2001.
PEREIRA, F.M.; NACHTIGAL, J.C. Botânica, biologia e cultivares de figueira. In: CORREA, L. de S.; BOLIANI, A.C. Cultura da figueira do plantio à comercialização. Ilha Solteira: FAPESP, 1999. p. 25-36.

PIMENTEL, M.C.G. Indução de aberrações cromossômicas estruturais em milho (Zea mays L.) por radiação gama. 1990. 86 f. Dissertação (Mestrado em Genética e Melhoramento) - Universidade Federal de Viçosa, Viçosa, 1990.

PREDIERI, S. Mutation induction and tissue culture in improving fruits. Plant Cell, Tissue and Organ Culture, Dordrechet, v.64, p.185-210, 2001.

RAGA, A.; SOUZA FILHO, M. F. Captura de Zaprionus indianus (Gupta) (Dip.: Drosophilidae) em frascos de plásticos com iscas alimentares na cultura do figo. Revista de Agricultura, Piracicaba, v.78, p.323-329, 2003.

RAIJ, B.V.; CANTARELLA, H.; QUAGGIO J.A.; FURLANI, A.M.C. Recomendações de adubação e calagem para o Estado de São Paulo. 2.ed. Campinas: IAC-Fundag, 1997. (Boletim Técnico, 100).

RIGITANO, O. A figueira cultivada no Estado de São Paulo. 1955. 59 f. Tese (Doutorado em Fitotecnia) - Escola Superior de Agricultura "Luiz de Queiroz”, Universidade de São Paulo, Piracicaba, 1955.

ROCHA, F.; BARILI, L.D.; GARCIA, S.H.; MODENA, R.; COIMBRA, J.L.M., GUIDOLIN, A.F., BERTOLDO, J.G. Seleção em populações mutantes de feijão (Phaseolusvulgaris L.) para caracteres adaptativos. Biotemas, Florianópolis, v.22, n.2, p. 19-27, 2009.

SANTOS, P. C.; CORREA, L. S.; TULMANN NETO, A.; BOLIANI, A. C. Sensitividade de estacas de figo à radiação gama. Revista Brasileira de Genética, Ribeirão Preto, v.20, n.3, p.150, 1997. 